$\mathrm{DE}$

M E D I C I N A

T R O P I C A L

$\mathrm{DE}$

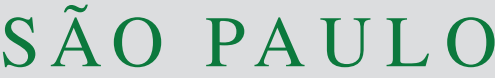

JOURNAL OF THE SÃO PAULO INSTITUTE OF TROPICAL MEDICINE

(1)Universidade do Estado do Rio de Janeiro, Hospital Universitário Pedro Ernesto, Núcleo Perinatal, Rio de Janeiro, Rio de Janeiro, Brazil

(2)Universidade do Estado do Rio de Janeiro, Faculdade de Ciências Médicas, Rio de Janeiro, Rio de Janeiro, Brazil.

${ }^{(3)}$ Centro Universitário Serra dos Órgãos, Teresópolis, Rio de Janeiro, Brazil

(4)Escola Nacional de Saúde Pública Sergio Arouca, Rio de Janeiro, Rio de Janeiro, Brazil

(5) Universidade do Grande Rio, Duque de Caxias, Rio de Janeiro, Brazil

Correspondence to: Luciane Rodrigues Pedreira de Cerqueira Universidade Estadual do Rio de Janeiro, Hospital Universitário Pedro Ernesto, Rua Professor Manoel de Abreu, 500, CEP 20550-170, Vila Isabel, Rio de Janeiro, RJ, Brazil

Tel: +55 $02199963-4640$

E-mail: dralucerqueira@gmail.com

Received: 29 May 2017

Accepted: 28 September 2017

\section{The magnitude of syphilis: from prevalence to vertical transmission}

Luciane Rodrigues Pedreira de Cerqueira1, Denise L. M. Monteiro ${ }^{2,3}$, Stella R. Taquette $^{2}$, Nádia C. P. Rodrigues ${ }^{2,4}$, Alexandre J. B. Trajano ${ }^{2,5}$, Flavio Monteiro de Souza², Bianca de Melo Araújo²

\section{ABSTRACT}

Introduction: In 2013, the World Health Organization (WHO) reported that 1.9 million pregnant women were infected with syphilis worldwide, of which $66.5 \%$ had adverse fetal effects in cases of untreated syphilis. Congenital syphilis contributes significantly to infant mortality, accounting for 305,000 perinatal deaths worldwide annually. Aim: To estimate the prevalence of syphilis in parturients, the incidence of congenital syphilis and the vertical transmission rate. Material and methods: a cross-sectional study with data collected from 2041 parturients who had undergone treatment between 2012 and 2014 in the maternity section of the Pedro Ernesto Hospital of the State University of Rio de Janeiro, in the metropolitan area of Rio de Janeiro. The inclusion criterion was positive VDRL and treponemal test in a hospital environment. Results: the prevalence of syphilis in pregnant women was $4.1 \%$ in $2012,3.1 \%$ in 2013 and $5 \%$ in 2014, with official reporting of $15.6 \%, 25.0 \%$ and $48.1 \%$, respectively. The incidence of congenital syphilis (CS) was 22/1,000 in live births (LB) in 2012; 17/1,000 LB in 2013 and 44.8/1,000 LB in 2014. CS underreporting during the period was $6.7 \%$. Vertical transmission occurred in $65.8 \%$ of infants from infected mothers. It was concluded that, in $34.6 \%$ of the CS cases, maternal VDRL titers were $=1 / 4$. Conclusion: Results demonstrate the magnitude of the disease, fragility of the reporting system in the assessment of the actual prevalence, impact on perinatal outcomes, and they are a warning about the real situation of syphilis, which is still underestimated in the State.

KEYWORDS: Syphilis. Gestation. Congenital syphilis. Prevalence. VDRL. Treponemal tests. Treponema pallidum.

\section{INTRODUCTION}

Syphilis is a sexually transmitted disease caused by the bacterium Treponema pallidum. Infection can be transmitted to the unborn child through the placenta at any gestational stage. In exceptional cases, syphilis can be transmitted at birth through the child's contact with the birth canal, when there are maternal genital lesions (direct transmission). Syphilis may only be transmitted through breastfeeding if there are breast syphilis lesions ${ }^{1}$.

Congenital infection is associated with adverse outcomes, including: perinatal death, preterm birth, low birth weight, congenital anomalies, active syphilis in the newborn (NB), and long-term sequelae, such as deafness and neurological impairment ${ }^{2}$.

There is a significant global increase in the prevalence of syphilis in pregnant women, despite all efforts from governments to control the disease. In 2013, the WHO reported 1.9 million pregnant women infected with syphilis worldwide, with $66.5 \%$ 
of adverse fetal outcomes occurring in cases of untreated syphilis $^{3}$. Congenital syphilis significantly contributes to infant mortality, accounting for 305,000 perinatal deaths per year worldwide 4 . There are more newborns affected by syphilis than by any other neonatal infection. It is estimated that 520,000 adverse fetal outcomes occur worldwide each year, making congenital syphilis more common than congenital HIV infection ${ }^{5}$. In areas where syphilis is prevalent, about half of the stillbirth rate may have been caused solely by this infection ${ }^{6}$. The direct medical cost associated with adverse fetal outcomes resulting from syphilis is U\$ 309 million dollars a year ${ }^{4}$.

High rates of syphilis in parturients mean a high incidence of congenital syphilis and millions of missed opportunities to save lives during pre-natal care. Over the past ten years, the infant mortality rate due to syphilis increased 150\% in Brazil, from 2.2 per 100,000 live births (LB) in 2004 to 5.5 per 100,000 LB in 2013. By 2015, the State of Rio de Janeiro had the highest rate of syphilis during pregnancy $(2.2 \%)$ and of congenital syphilis in the country (16 cases per $1,000 \mathrm{LB})^{7,8}$.

The last syphilis monitoring study in pregnant women performed in Brazil in 2014, with a statistical sample from public and private hospitals, estimated the prevalence of syphilis at $1.02 \%$, with no significant regional differences ${ }^{9}$.

According to the prediction curve of the disease, the Ministry of Health (MH) expected 40,000 cases in pregnant women in Brazil in 2016. An epidemic of the disease in the country was confirmed by the Ministry of Health in 2016. The increased incidence of syphilis in pregnant women is alarming ${ }^{8}$. In 2015, according to the MH, the States of Rio de Janeiro and Mato Grosso do Sul were the most affected in the country, reaching a syphilis rate in pregnant women of $2.2 \%$.

The national studies show differences in the prevalence of the disease according to the region studied, with rates ranging around $0.4 \%$ in Vitória (Espírito Santo) ${ }^{10}$, Itajaí $\left(\right.$ Santa Catarina) ${ }^{11}$ and $7.7 \%$ in Fortaleza (Ceará) ${ }^{12}$.

The analysis of international studies on the subject in countries such as Haiti ${ }^{13}$ shows that the prevalence of syphilis in pregnant women reaches $7.6 \%$, while in other countries, such as Canada, syphilis has already been eliminated ${ }^{14}$. The WHO certified Cuba in 2013 as the first country to eliminate the vertical transmission of HIV and syphilis during pregnancy. Six other countries are currently able to request the WHO to validate the double elimination, including Canada and the United States ${ }^{15}$.

\section{Aim}

To estimate the prevalence and coverage of syphilis reporting in parturients, the incidence of congenital syphilis and its corresponding underreporting, as well as the rate of vertical transmission of infection.

\section{MATERIALS AND METHODS}

Study design

Cross-sectional study.

\section{Studied population}

A total of 2,041 pregnant women were recruited after admission to a public hospital in the metropolitan region of Rio de Janeiro, between January 2012 and December 2014. The institution involved in the study was the Pedro Ernesto Hospital of the State University of Rio de Janeiro (HUPE / UERJ).

\section{Data collection}

At HUPE, blood samples are routinely collected for syphilis investigation upon admission, with both nontreponemal testing (VDRL-Venereal Disease Research Laboratory) and confirmatory treponemal test (TPHATreponema Pallidum Hemagglutination). The confirmation via the treponemal test is important due to the possibility of a false-positive result. All the tests were performed in the clinical analysis laboratory of HUPE. According to the protocol of the Brazilian Ministry of Health, blood samples are collected for syphilis testing from all parturients. An active search of syphilis serology results (treponemal and non-treponemal tests) with the respective titrations was conducted by accessing the database of the hospital laboratory. A thorough review of the medical records of pregnant women and their newborns was also conducted. Data from the HUPE epidemiology service were evaluated in order to identify the total number of infected pregnant women and newborns, in order to avoid underestimating the results. A survey was conducted on the website of the State's Department of Health website to collect data on syphilis reports during pregnancy, as well as reports of congenital syphilis on the SINAN (National Disease Notification System) and the number of live births in the SINASC (Live Births Notification System).

\section{Inclusion criterion}

The following parturients were eligible for the study: pregnant women admitted for delivery with a live fetus of any gestational age and weight, stillbirths with gestational age equal to 22 weeks or weight equal to 500 grams. 
The following cases were defined as syphilis during pregnancy: all cases in which the parturient was admitted with laboratory evidence of positive VDRL (any titer) collected at the time of admission and confirmed by the treponemal test; all cases in which the parturient's newborn (stillbirth or live birth) has been reported as a case of congenital syphilis (CS), identified in any of the information systems consulted.

\section{Exclusion criterion}

The following parturients were excluded: the ones with positive VDRL resulting from adequately treated previous syphilis (complete treatment with benzathine penicillin, according to the clinical stage of the disease, complete treatment of the partner, documentation confirming the couple's treatment, drop in VDRL titers after adequate treatment, treatment completed more than 30 days before delivery).

\section{Variable definition}

The following situations were included as CS cases: all the gestation products (live births or stillborn) identified in any of the information systems as premature congenital syphilis; all newborns with VDRL titers higher than the maternal ones; all newborns with clinical manifestations suggestive of syphilis or complementary tests pointing to $\mathrm{CS}^{7}$.

\section{Epidemiological definitions}

According to the recommendation of the strategic management of the $\mathrm{MH}$, the prevalence of syphilis in pregnant women is the ratio of the number of cases of syphilis detected in pregnant women to every 1,000 live births, within a geographical space and for a given period. For the purpose of calculating the prevalence, we used as the numerator the number of cases of syphilis detected in pregnant women, in a given notification year and place of residence multiplied by 1,000 and divided by the total number of live births in the same place and in the same reported year ${ }^{16}$. The numerator could be found in the SINAN (national disease notification system) and the denominator in the SINASC (live births information system).

For the calculation of the prevalence of parturients as a percentage, the number of cases of syphilis in parturients identified in the study was used as the numerator; the number of live births in that place and period, multiplied by 100 as the denominator.

To evaluate underreporting, we divided the number of parturients with syphilis in SINAN by the number of parturients with syphilis in hospitals x 100 .
Following the $\mathrm{MH}$ recommendation for the calculation of the CS incidence, the number of CS cases identified in the study was used as the numerator and the number of live births at that location and period, multiplied by 1000, as the denominator.

In order to evaluate the underreporting of congenital syphilis, we divided the number of CS cases by the number of cases reported in SINAN x 100.

\section{Data analysis}

The sample size was calculated considering an expected prevalence of syphilis in pregnant women according to the $\mathrm{MH}$ in public hospitals of $1.1 \%$ in 2006, in Brazil ${ }^{9}$. To perform this calculation, assuming an error of 5\% and a confidence interval (CI) of $95 \%$ the sample size was calculated to be 17 for $95 \% \mathrm{CI}$ and 46 for $99,9 \% \mathrm{CI}$.

Collected variables were used in the comparative analyzes to identify prevalence factors. The results were expressed as percentages. The process of entering and analyzing statistical data was performed through the EPIINFO 3.5.2 version 3.0.1 computing program.

\section{Considerations on ethical aspects}

The research project was carried out within the standards required by the Declaration of Helsinki and Resolution 466 of December 12, 2012, and approved by the Research Ethics Committee of the UERJ (COEP) in July 2012, process $\mathrm{N}^{\circ}$ 034.3.2012 and sponsored by FAPERJ, process $\mathrm{N}^{\mathrm{o}}$ E-26/110.351/2012.

\section{RESULTS}

A total of 2,041 parturients were studied in HUPE: 735 in 2012, 664 in 2013 and 642 in 2014. After the exclusion of 19 pregnant women due to serological scarring or false-positive results (treponemal negative test), 79 cases of parturients with syphilis were identified: 32 cases in 2012, 20 in 2013 and 27 in 2014. Access to the result of the treponemal and non-treponemal tests for syphilis was obtained from all the pregnant women admitted during the period.

The search on SINASC, considering HUPE as the place of birth, totaled 1,956 live births in HUPE for the three years studied, with 773 live births in 2012, 647 in 2013 and 536 in 2014. The prevalence of syphilis in the HUPE, using the number of live births officially described in SINASC as the denominator, was $4.1 \%$ in 2012, 3.1\% in 2013 and 5.0\% in 2014. Between 2012 and 2014, there was an increase on the prevalence of the disease (Table 1). 
Table 1 - Prevalence of syphilis in parturients between 2012 and 2014 at HUPE, Rio de Janeiro, Brazil

\begin{tabular}{lccccc}
\hline Year & Frequency & LB SINASC & $\%($ CL 95\%) & Prevalence & $\begin{array}{c}\text { Prevalence } \\
\text { (cases/1.000 LB) }\end{array}$ \\
\hline 2012 & 32 & 773 & $4.1(2.9-5.8)$ & 41.4 & 4.1 \\
2013 & 20 & 647 & $3.1(1.9-4.7)$ & 31.0 & 3.1 \\
2014 & 27 & 536 & $5.0(3.4-7.2)$ & 50.4 & 5.0 \\
\hline Total & 79 & 1956 & $4.0(3.2-5.0)$ & 40.3 & 4.0 \\
\hline
\end{tabular}

Legend: live births (LB); live birth information system (SINASC); confidence limit (CL)

Source: the authors, 2017

The search on SINAN came up with 23 cases of syphilis in HUPE for the three years studied $(2012=5,2013=5$ and $2014=13$ ). The research showed 79 cases in the three years $(2012=32,2013=20$ and $2014=27)$.

Therefore, $15.6 \%$ of cases in 2012, 25.0\% in 2013 and $48.1 \%$ in 2014 were reported, which shows a significant increase for the period.

Three parturients $(3.8 \%)$ from HUPE were double counted in the prevalence calculation, when they were admitted with syphilis at the time of delivery of subsequent pregnancies. One of the three parturients had VDRL titer $=1 / 4$ and progressed to $1 / 128$ in the next gestation. The other two had $1 / 32$ titers in the first gestation and had titers of $1 / 32$ and $1 / 128$, respectively, in subsequent pregnancies.

The incidence of CS was 22/1,000 LB in 2012, 17/1,000 LB in 2013 and 44.8/ 1,000 LB in 2014. The notification of congenital syphilis reached $92.3 \%$ of the cases and only four cases were not officially reported. The present study demonstrated a vertical transmission rate of $65.8 \%$, with 52 newborns affected by congenital syphilis.

From the group of parturients with vertical transmission of the disease, 18 mothers had VDRL titers $=1 / 4$, corresponding to $34.6 \%$ of the cases of congenital syphilis. The vertical transmission occurred in two consecutive pregnancies in one case that was within the low titers group (=1/4).

\section{DISCUSSION}

The latest national studies in public or public-private hospitals that monitor the prevalence of syphilis in the country demonstrated a reduction in the prevalence of syphilis among parturients in Brazil. Sentinel studies revealed a prevalence of $1.6 \%{ }^{17}$ in 2004 and $1.02 \%$ in 2014.

However, the present study does not confirm this trend and demonstrates that the disease is not under control in the State of Rio de Janeiro. In 2014, the prevalence rate of $5.0 \%$ was four-fold higher than the one registered in the country in 2014 by Domingues et al. ${ }^{19}$ and twice higher than the one registered in the State of Rio de Janeiro in 2008 by the same author ${ }^{18}$.
The results are similar to those described by the $\mathrm{MH}$ regarding the ascending curve of the disease in recent years, but they express a significantly higher prevalence when compared with data from the epidemiological surveillance agencies for the same period. In 2014, although the State of Rio de Janeiro had the highest syphilis rate in pregnant women in the country (2.2\%), the prevalence registered at HUPE was 2.3 times higher than the official one ${ }^{10}$.

The prevalence registered in 2012 was similar to the one of the Republic of Congo in Africa (4.2\%) ${ }^{19}$. It was superior to levels in other Latin American countries in the three years studied and it is a warning regarding the epidemiological situation of syphilis in the State ${ }^{20}$.

For some authors, the increase in the disease prevalence in the country may be associated with the improvement in the diagnosis and reporting systems, and not necessarily with the rise in the total number of cases. However, for some infectologists, the rising prevalence is due to the increasing practice of unprotected sex, which would intensify the number of cases of syphilis in the adult population and, consequently, during pregnancy. For others, there are flaws in the gestation treatment of prenatal services, in both diagnosis and treatment of the pregnant women and their partners $^{7,21}$.

A possible limitation of the present study is the selection bias, since the prevalence can be overestimated by including parturients with serological scarring $(<1 / 8)$ in their calculation, even after the meticulous evaluation of the medical records and considering epidemiological history. The MH considers low VDRL titers when diagnosing syphilis, due to the variations in readings and the lack of detection by the tests. All the national studies consulted, including the sentinel studies in parturients, used any VDRL title for the calculation of the prevalence in its methodology ${ }^{9,22}$. Furthermore, several authors have already described the clinical significance of low titers of VDRL in the diagnosis of congenital syphilis ${ }^{23}$.

Although there has been a substantial increase in the reporting of syphilis in parturients in HUPE between 2012 and 2014, it has not reached half of the cases, which 
demonstrates how fragile the epidemiological surveillance system is in identifying and reporting all cases. The considerable increase in the coverage of notifications follows the increased number of notifications observed in Brazil, which, according to the $\mathrm{MH}$, is related to the Rede Cegonha program, which increased the coverage of pregnant women testing and follow-up of cases ${ }^{24}$. In Brazil, between 2012 and 2013 , there was a $25 \%$ increase in the number of syphilis reports in pregnant women, and $23 \%$ if only the Southeast region is considered, which is responsible for $45.9 \%$ of the country's notifications. The increase of the number of notifications in the State of Rio de Janeiro was $16 \%$. In the country, São Paulo is the State with the highest number of notifications, followed by the State of Rio de Janeiro ${ }^{25}$.

Although the surveillance agencies considered underreporting for the purposes of disease monitoring, the present study shows that the level of underreporting was higher than estimated and should not be used as a basis for calculation. Without the proper notification, there is a tendency to underestimate the problem. However, the underreporting found in HUPE in 2013 is similar to the one described by Cavalcante et al. ${ }^{26}$ in Fortaleza and Domingues et al. ${ }^{18}$ in SUS units (state health clinics and hospitals) in the city of Rio de Janeiro, where underreporting was $73 \%$, $70.3 \%$ and $76.1 \%$, respectively, demonstrating the fragility of the information services in Brazil to work as a basis for promoting measures to combat the disease.

The high prevalence of the disease among the parturients of the present study resulted in an incidence of congenital syphilis (26.6 per 1,000 LB) greater than that reported in the State of Rio de Janeiro in 2015 (16 per 1,000 LB $)^{10}$ and at least five-fold greater than the incidence of the disease in Brazil, according to the Nascer Study $(3.51 \text { per } 1,000 \mathrm{LB})^{27}$.

Regarding the notification of congenital syphilis, the present study reached more than $90 \%$, a result far superior to that reported by the $\mathrm{MH}$, which estimates notification at only $17.4 \%$ of the cases of CS in the country ${ }^{24}$. HUPE is located in the capital of the State of Rio de Janeiro and, according to the epidemiological bulletin of the State Health Department, it is the city with the highest number of notifications of CS in the State $(63.5 \%)^{25}$.

The high vertical transmission rate of syphilis in this study $(65.8 \%)$ shows the high prevalence of syphilis among parturients, since among the various diseases that can be transmitted during the puerperal-pregnancy cycle, syphilis is the one that presents the greater chances of transmission ${ }^{28}$. Kupek et al. ${ }^{11}$ showed similar rates $(68.9 \%)$. Domingues et al. ${ }^{18}$ and the $\mathrm{MH}^{7}$, however, estimated lower rates of vertical transmission, $34.8 \%$ in Rio de Janeiro and $25 \%$ in Brazil, respectively.

The occurrence of maternal syphilis in a subsequent gestation demonstrated that a prior gestation with syphilis did not eliminate the risk of the disease in future pregnancies. The recurrence of syphilis in two distinct pregnancies is the major sign of the inefficiency of the health system in properly conducting these cases.

Fetal infection occurred even in the presence of low VDRL maternal titers. The lack of proper consideration of low titers of VDRL by the health professionals is still a barrier to the control of congenital syphilis. In a study with health professionals, it was observed that only $48 \%$ had adequate knowledge about the management of syphilis, especially regarding the treatment of pregnant women with low titration ${ }^{29}$.

Since syphilis is an easily diagnosed disease that has an established treatment and generates low costs for testing and treatment during pregnancy, it should be possible to control the disease. However, the disease continues to advance in Brazil in alarming numbers.

\section{CONCLUSIONS}

The estimated prevalence of syphilis in pregnant women in Rio de Janeiro is at least twice as high as previously reported by regional studies and epidemiological surveillance data in the State, reaching levels found in African countries and higher than the figures for other countries in Latin America. These values are a warning on the magnitude of the disease in the State of Rio de Janeiro, its upward curve and its consequences. Our reporting system has proven to be fragile and unable to assess the current prevalence of syphilis in Rio de Janeiro, which is underestimated. Due to the high prevalence of syphilis among parturients, there was a high rate of CS and vertical transmission that occurred even in pregnant women with low VDRL titers, emphasizing the importance of evaluating low titers in the management of these patients.

It is a responsibility of the health professionals, who daily handle this sad reality, to strive for excellence in caring for pregnant women. Even in the $21^{\text {st }}$ century, the high rates of syphilis in parturients and CS in Brazil are still ignored and underestimated.

\section{REFERENCES}

1. Thomas DD, Navab M, Haake DA, Fogelman AM, Miller JN, Lovett MA. Treponema pallidum invades intercellular junction of endothelial cell monolayers. Proc Natl Acad Sci U S A. 1988; 85:3608-12.

2. Organização Mundial de Saúde. Eliminação mundial da sífilis congénita: fundamento lógico e estratégia para acção. Genebra: OMS; 2008. 
3. Klausner JD. The sound of silence: missing the opportunity to save lives at birth. Bull World Health Organ. 2013;91:158-158A.

4. World Health Organization. Department of Reproductive Health and Research. Investment case for eliminating mother-to-child transmission of syphilis: promoting better maternal and child health and stronger health systems. Geneva: WHO; 2012.

5. Newman L, Kamb M, Hawkes S, Gomez G, Say L, Seuc A, et al. Global estimates of syphilis in pregnancy and associated adverse outcomes: analysis of multinational antenatal surveillance data. PLoS Med. 2013;10:e1001396.

6. McClure EM, Goldenberg RL. Infection and stillbirth. Semin Fetal Neonatal Med. 2009;14:182-9.

7. Brasil. Ministério da Saúde. Secretaria de Vigilância em Saúde. Departamento de DST, AIDS e Hepatites Virais. Boletim epidemiológico sífilis 2015. Brasília: Ministério da Saúde; 2015. [cited 2017 Sept 28]. Available from: http://www.aids. gov.br/es/node/88

8. Brasil. Ministério da Saúde. Secretaria de Vigilância em Saúde. Departamento de DST, AIDS e Hepatites Virais. Nota informativa No 06/2016/GAB/DDHAV/SVS/MS. Brasília: Ministério da Saúde; 2016. Available from: http://www. aids.gov.br/pt-br/legislacao/nota-informativa-no-0062016gabddahvsvsms

9. Domingues RM, Szwarcwald CL, Souza Junior PR, Leal MC. Prevalence of syphilis in pregnancy and prenatal syphilis testing in Brazil: birth in Brazil study. Rev Saude Publica. 2014;48:766-74.

10. Miranda AE, Filho ER, Trindade CR, Gouvêa GM, Costa DM, Ge Oliveira T, et al. Prevalência de sífilis e HIV utilizando testes rápidos em parturientes atendidas nas maternidades públicas de Vitória, Estado do Espírito Santo. Rev Soc Bras Med Trop. 2009;42:386-91.

11. Kupek E, Oliveira JF. Transmissão vertical do HIV, da sífilis e da hepatite B no município de maior incidência de AIDS no Brasil: um estudo populacional no período de 2002 a 2007. Rev Bras Epidemiol. 2012;15:478-87.

12. Araújo MA, de Freitas SC, de Moura HJ, Gondim AP, da Silva RM. Prevalence and factors associated with syphilis in parturient women in Northeast, Brazil. BMC Public Health. 2013;13:206.

13. Lomotey CJ, Lewis J, Gebrian B, Bourdeau R, Dieckhaus K, Salazar JC. Maternal and congenital syphilis in rural Haiti. Rev Panam Salud Publica. 2009;26:197-202.

14. Kuo M, Money DM, Alvarez M, Buxton JA, Krajden M, Lester RT, et al. Test uptake and case detection of syphilis, HIV, and hepatitis $\mathrm{C}$ among women undergoing prenatal screening in British Columbia, 2007 to 2011. J Obstet Gynaecol Can. 2014;36:482-90.

15. World Health Organization. Who validates elimination of motherto-child transmission of HIV and syphilis in Cuba. Geneva: WHO; 2015. [cited 2017 Sept 28]. Available from: http://www. who.int/mediacentre/news/releases/2015/mtct-hiv-cuba/en/

16. Brasil. Ministério da Saúde. Sala de Apoio à Gestão Estratégica. Nota técnica: sífilis congênita: indicadores epidemiológicos. [cited 2017 Sept 28]. Available from: http://www.conass. org.br/guiainformacao/notas_tecnicas/NT17-SIFILIS-\%20 Indicadores-epidemiologicos.pdf

17. Brasil. Ministério da Saúde. Secretaria de Vigilância em Saúde. Programa Nacional de DST e Aids. Bol Epidemiol Aids DST 2006. [cited 2017 Sept 28]. Available from: http://www.aids. gov.br/es/node/82

18. Domingues RM, Saracen V, Hartz ZM, Leal MC. Sífilis congênita: evento sentinela da qualidade da assistência pré-natal. Rev Saude Publica. 2013;47:147-56.

19. Taylor MM, Ebrahim S, Abiola N, Kinkodi DK, Mpingulu M, Kabuayi JP, et al. Correlates of syphilis seropositivity and risk for syphilis-associated adverse pregnancy outcomes among women attending antenatal care clinics in the Democratic Republic of Congo. Int J STD AIDS. 2014;25:716-25

20. World Health Organization. Syphilis in pregnancy. Geneva: WHO; 2017. [cited 2017 Sept 28]. Available from: http://www.who. int/gho/sti/pregnancy/en/

21. Szwarcwald CL, Barbosa Junior A, Miranda AE, Paz LC. Resultados do estudo sentinela parturiente, 2006: desafios para o controle da sifílis congênita no Brasil. DST J Bras Doenças Sex Transm. 2007;19:128-33.

22. Cambricoli F. Casos de grávidas com sífilis aumentam 1.047\% entre 2005 e 2013. J Estado Sao Paulo. 2015 May 29. [cited 2017 Sept 28]. Available from: http://saude.estadao.com.br/ noticias/geral,notificacoes-de-casos-de-gravidas-com-sifilisaumentam-1047,1696341

23. Nonato SM, Melo AP, Guimarães MD. Sífilis na gestação e fatores associados à sífilis congênita em Belo Horizonte-MG, 20102013. Epidemiol Serv Saude. 2015;24:681-94.

24. Brasil. Ministério da Saúde. Secretaria de Vigilância em Saúde. Departamento de DST, AIDS e Hepatites Virais. Bol Epidemiol Sífilis 2012. [cited 2017 Sept 28]. Available from: http://www. dst.uff.br/publicacoes/Boletim_epidem_sifilis_2012.pdf

25. Rio de Janeiro. Secretaria de Estado de Saúde. Subsecretaria de Vigilância em Saúde. Superintendência de Vigilância Epidemiológica e Ambiental. Boletim epidemiológico DST/ AIDS e hepatites virais 2014. Rio de Janeiro: Secretaria de Estado de Saúde; 2014. [cited 2017 Sept 28]. Available from: http://www.riocomsaude.rj.gov.br/Publico/MostrarArquivo. aspx?C=sF6igzRT/p4=

26. Cavalcante MS, Ramos Jr AN, Pontes LR. Relacionamento de sistemas de informação em saúde: uma estratégia para otimizar a vigilância das gestantes infectadas pelo HIV. Epidemiol Serv Saude. 2005;14:127-33.

27. Domingues RM, Leal MC. Incidência da sífilis congênita e fatores associados à transmissão vertical da sífilis:dados do estudo Nascer no Brasil. Cad Saude Publica. 2016;32:e00082415. 
The magnitude of syphilis: from prevalence to vertical transmission

28. Nascimento MI, Cunha AA, Guimarães EV, Alvarez FS, Oliveira SR, Villas Bôas EL. Pregnancies complicated by maternal syphilis and fetal death. Rev Bras Ginecol Obstet. 2012;34:5662.
29. Domingues RM, Hartz ZM, Leal MC. Avaliação das ações de controle da sífilis e do HIV na assistência pré-natal da rede pública do município do Rio de Janeiro, Brasil. Rev Bras Saude Matern Infant. 2012;12:269-80. 